\title{
Surveillance of Healthcare-Associated Infections (HAI) in an Adult Surgical Intensive Care Unit (ICU) in the Republic of South Africa
}

\author{
Hakizimana $B^{*}$ \\ Academic Unit for Infection Prevention and Control, Stellenbosch University, Tygerberg, Cape Town, South Africa
}

\begin{abstract}
Background: Patients being treated in ICUs are at high risk of developing infection due to invasive procedures, frequent underlying health problems and immunosuppression resulting from their critical illness and co-morbidities. This project aimed to assess the incidence of HAI in A1 Adults Surgical ICU at Tygerberg Hospital and to improve infection prevention and control practices.

Methods: This was a prospective observational study conducted during a period of 5 weeks, starting from 08 September to 15 October 2014. During the first four weeks, all new bacterial positive isolates from A1 Surgical ICU were collected daily, and then patient clinical data collected from patient files and from clinician's interactive (doctors and nurses). The diagnosis of HAI was made based on the NHSN definitions. Wound contamination class used is the one described by Altemeier. Direct observation on hand hygiene practice was done to check whether any correlation between hand hygiene compliance and HAI rate. Data was analysed using Ms Excel.

Results: There was a very high LRTI with 81.8 infections per 1000 IP-Days per month, followed by SSI with 31.7 infections per 1000 IP-Days and BSI with 26.4 infections per 1000 IP-Days per month. Acinetobacter baumannii was the most common organism representing $31 \%$ of all infections. VAP incidence density was 12.3 infections per 1000 ventilator-days per month, while CAUTI incidence density was 7.9 infections per 1000 catheter-days per month. There was no case of CLABSI during the surveillance period. Multidrug resistant organisms represented $65.4 \%$ of all isolated organisms causing HAI.

Conclusion: HAI rates were very high for LRTI (81.8/1000 IP-Days), SSI (31.7/1000 IP-Days) and BSI (26.4/1000 IP-Days). MDR is very high (65.4\%). HH compliance was very scared (29.3\%). Only CLABSI bundle was implemented in A1 Surgical ICU. Bundles of care other than CLABSI such as VAP, CAUTI should be implemented to reduce HAls. The clinical staff should comply with IPC precautions, especially standard precautions to reduce the risk of patients from getting HAls.
\end{abstract}

Keywords: Healthcare-associated infections; Intensive care unit; IPdays; Multidrug resistant organisms; IPC precautions; Bundles of care; Hand hygiene compliance

\section{Introduction}

Healthcare-associated infection (HAI) was defined as a localized or systemic condition that results from an adverse reaction to the presence of an infectious agent(s) or its toxin(s) that occurs during an acute healthcare facility admission, for which there is no evidence that infection was present or incubating at admission, and meets body sitespecific criteria [1,2].

Patients being treated in intensive care units (ICUs) are at an increased risk of developing infection due to invasive procedures, frequent underlying health problems and immunosuppression resulting from their critical illness and co-morbidities [3,4].

The impact of HAI implies prolonged hospital stay, long-term disability, increased resistance of microorganisms to antimicrobials, a massive additional financial burden for health systems, high costs for patients and their families, and excess deaths $[3,4]$.

Surveillance is an important tool to assess the incidence of healthcare-associated infections (HAI) and to improve infection control measures in healthcare facilities [5].

The aim of this study was to assess the incidence of healthcareassociated infections (HAI) in A1 Adults Surgical ICU and to improve infection prevention and control practices. Its objectives were: determine if the reported positive isolate was infection, colonization or contamination, classify the reported positive isolates (HAI,
Community-acquired infection [CAI], colonization or contamination), evaluate infection prevention and control (IPC) containment measures in place, determine the rate of healthcare-associated infection, determine the resistance patterns, determine the risk factors, and define discharge details and patient outcomes.

\section{Methods}

This study was conducted at Tygerberg Hospital, in surgical intensive care unit, ward A1 West. This was a 14-bedded ward with bed spacing of 2.5 metres; it was conducted during the period of 5 weeks, from 08 September to 15 October 2014. The study was part of the Surveillance and Research Methodology for Postgraduate Diploma in Infection Prevention and Control. Tygerberg Hospital is a 1310 beds academic tertiary referral hospital, located in Parow, Cape Town. The hospital was officially opened in 1976 and is the largest hospital in the Western Cape and the second largest hospital in South Africa. The

*Corresponding author: Hakizimana B, Academic Unit for Infection Prevention and Control, Faculty of Medicine and Health sciences, Stellenbosch University, PO Box 19063, Tygerberg 7505, Cape Town, South Africa, Tel: +250788594903 E-mail: bonihak@yahoo.fr

Received: September 07, 2017; Accepted: September 13, 2017; Published: September 20, 2017

Citation: Hakizimana B (2017) Surveillance of Healthcare-Associated infections (HAI) in an Adult Surgical Intensive Care Unit (ICU) in the Republic of South Africa. J Infect Dis Med 2: 115. doi: 10.4172/2576-1420.1000115

Copyright: ( $\odot 2017$ Hakizimana B. This is an open-access article distributed under the terms of the Creative Commons Attribution License, which permits unrestricted use, distribution, and reproduction in any medium, provided the original author and source are credited. 
investigator used the validated tools which were: (1) HAI surveillance form: this was the tool used by IPC team in Tygerberg Hospital. (2) The Infection Control Assessment Tool (ICAT), $2^{\text {nd }}$ edition-Facility Checklist for hand hygiene practices which was used in all healthcare facilities of South Africa [6-21].

During the first four weeks, all new positive isolates from blood culture, catheter tip, central venous pressure (CVP) tip, bronchial washing, bronco-alveolar lavage, sputum, tracheal aspirate, urine, pus swab, wound swab, abdominal fluid, tissue, pus, and eye tissue were collected from daily laboratory report, and then patients visited and clinical data collected and evaluated. The fifth week was reserved to follow-up the outcome of the recruited patients. All four types of HAI such as bloodstream infection (BSI), surgical site infection (SSI), ventilator-associated pneumonia (VAP) and urinary tract infection (UTI) were concerned by the study.

The investigator collected data related to patient information, comorbidities, ward movement, antibiotic use, medical devices, laboratory (bacterial and white blood cells [WBC]), surgical interventions, vital signs, diagnoses (differential, primary and secondary), IPC measures in place, discharge details and patient outcome (cured, improved, transferred, deceased, still in the ward). The diagnosis of HAI was made based on the National Health and Safety Network (NHSN) definitions [11]. VAP was identified using a combination of radiologic, clinical, and laboratory criteria. VAP was considered present in patients on mechanical ventilation with a chest $\mathrm{X}$-ray showing a new or progressive infiltrate, consolidation, cavitation, or pleural effusion. Clinical criteria included at least one of the following: new onset of purulent sputum, a change in character of sputum, and isolation of a bacterial agent from tracheal aspirate/brushing or broncho-alveolar lavage. Central line-associated bloodstream infection (CLABSI) was defined as a laboratory-confirmed infection in a patient with a central line in place for $\geq 48 \mathrm{~h}$ who had a recognized pathogen isolated from one or more percutaneous blood cultures, and when the infection was not related to an infection at another site. Isolation of the same organism (i.e., identical species and antibiogram) from a semi-quantitative or quantitative culture of a catheter segment and from the blood (preferably drawn from a peripheral vein) of a patient with accompanying clinical symptoms of BSI (fever $\geq 38^{\circ} \mathrm{C}$, chills, or hypotension) and no other apparent source of infection was required. For common skin contaminants including diphtheroids (Corynebacterium spp), Bacillus spp (not Bacillus anthracis), Propionibacterium spp, coagulase-negative staphylococci (including Staphylococcus epidermidis), viridans group streptococci, Aerococcus spp, and Micrococcus spp, two or more blood cultures drawn on separate occasions were required to be positive. Catheter-associated urinary tract infection (CAUTI) was defined in a patient with a urinary catheter in place exhibiting either one of the following two criteria: (1) one or more of the following signs and symptoms with no other recognized cause: fever (temperature $\geq 38^{\circ} \mathrm{C}$ ), urgency, supra-pubic tenderness, and urine culture $\geq 10^{5}$ colony-forming unit $(\mathrm{CFU}) / \mathrm{ml}$, with no more than two species of microorganism isolated; or (2) positive dipstick analysis for leukocyte esterase or nitrate and pyuria (urine specimen with $>10$ white blood cells $/ \mathrm{mm}^{3}$ or $<3$ white blood cells/high-power field of unspun urine), microorganisms seen on Gram stain of unspun urine, and a positive urine culture of $>10^{3}$ and $>10^{5} \mathrm{CFU} / \mathrm{ml}$ with no more than two species of microorganism isolated. HAI rates per 1000 in-patient days (IP-days) were calculated as the number of infections for each type of HAI divided by the total number of IP-days in A1 ICU. The bundle for CLABSI was implemented in A1 Surgical ICU in November 2012. Direct observation on hand hygiene practice was done to see if there is any correlation between hand hygiene compliance level and HAI rate in the ward.

All patients whose bacterial sample collected and the laboratory result became positive during the first four weeks of surveillance $\left(08^{\text {th }}\right.$ September, 2014 to $08^{\text {th }}$ October, 2014) were included in this study. Patients already have infection at the time or before the surveillance start period and patients whose bacterial sample collected after $08^{\text {th }}$ October, 2014 were excluded in this study. Cases were classified as: Healthcare-associate infection (HAI), Community-acquired infection (CAI), Colonization or Contamination. Data was analysed using Ms Excel.

\section{Results}

Hand hygiene compliance was $29.3 \%$ in general (Tables 1 and 2). It was $20.7 \%$ before patient contact and $37.9 \%$ after patient contact. Lower level of hand hygiene compliance found to be linked with high HAI rate in any healthcare facility [6-10]. There is a strong evidence that hand hygiene is the most effective measure to prevent the transmission of pathogens in healthcare facilities, thereby reducing the risk of healthcare-associated infection [6-10].

$86.2 \%(\mathrm{n}=29)$ of patients had infection, while 4 patients $(13.8 \%)$ were colonized (Table 3). Acinetobacter baumannii was the commonest organism causing infection in A1 Surgical ICU, and it was isolated from all sites, but firstly in tracheal aspirate (Figure 1). Wound swab was the most colonized site, and Pseudomonas was the commonest organism causing colonization (Figure 2). Acinetobacter baumannii, Methicillinresistant staphylococcus aureus (MRSA), Klebsiella pneumonia and Pseudomonas aeruginosa were the top four organism-causing infections (Table 4). Lower respiratory tract infection (LRTI) was the first type of infection found, followed by SSI and BSI (Figure 3). There were also three cases of clostridium infection during the surveillance period. The four CAI found have been caused by Escherichia coli $96.6 \%$ of patients required contact precautions, and the investigator found that IPC precautions have been initiated after getting instructions from

\begin{tabular}{|c|c|}
\hline $\begin{array}{l}\text { WoundContamination } \\
\text { class }\end{array}$ & Description \\
\hline W1 & $\begin{array}{l}\text { A clean wound is an uninfected operative wound } \\
\text { in which no inflammation is encountered and the } \\
\text { respiratory, alimentary, genital or uninfected urinary } \\
\text { tracts are not entered. In addition, clean wounds are } \\
\text { primarily closed and, if necessary, drained with closed } \\
\text { drainage. Operative incisional wounds that follow non- } \\
\text { penetrating trauma should be included in this category. }\end{array}$ \\
\hline W2 & $\begin{array}{l}\text { Clean-contaminated wounds are operative wounds } \\
\text { in which the respiratory, alimentary, genital or } \\
\text { uninfected urinary tracts are entered under controlled } \\
\text { condition and without unusual contamination. } \\
\text { Specifically operations involving the biliary tract, } \\
\text { appendix, vagina and oropharynx are included in this } \\
\text { category provided no evidence of infection or major } \\
\text { break in technique is encountered. }\end{array}$ \\
\hline W3 & $\begin{array}{l}\text { Contaminated wounds include open, fresh, } \\
\text { accidental wounds. In addition operations with major } \\
\text { breaks in sterile technique or gross spillage from the } \\
\text { gastrointestinal tract, and incisions in which acute, } \\
\text { non-purulent inflammation is encountered are included } \\
\text { in this category. }\end{array}$ \\
\hline W4 & $\begin{array}{l}\text { Dirty or infected wounds include old traumatic } \\
\text { wounds with retained devitalised tissue and those that } \\
\text { involve existing clinical infection or perforated viscera. } \\
\text { This definition suggests that the organisms causing } \\
\text { postoperative infection were present in the operative } \\
\text { field before the operation. }\end{array}$ \\
\hline
\end{tabular}

Table 1: Wound contamination classification by Altemeier et al. [21]. 
Citation: Hakizimana B (2017) Surveillance of Healthcare-Associated infections (HAI) in an Adult Surgical Intensive Care Unit (ICU) in the Republic of South Africa. J Infect Dis Med 2: 115. doi: 10.4172/2576-1420.1000115

Page 3 of 6

\begin{tabular}{|c|c|c|c|c|c|c|c|c|c|c|c|}
\hline \multirow{3}{*}{ Patient Contacts Number } & \multicolumn{11}{|c|}{ Date of observation: 22 Sep 2014 from 11:30 - 12:30 ( $60 \mathrm{~min}$ ) } \\
\hline & \multicolumn{3}{|c|}{ Type of Health Work } & \multicolumn{2}{|c|}{ Type of Patient Contact } & \multicolumn{3}{|c|}{$\begin{array}{c}\text { Type of HH before Patient } \\
\text { Contact }\end{array}$} & \multicolumn{3}{|c|}{$\begin{array}{c}\text { Type of HH after Patient } \\
\text { Contact }\end{array}$} \\
\hline & Doctor & Nurse & Other & Invasive & Non-invasive & HW & AHR & None & HW & AHR & None \\
\hline 29 & 12 & 16 & 1 & 15 & 14 & 2 & 4 & 23 & 10 & 1 & 18 \\
\hline$\%$ & 41.4 & 55.2 & 3.4 & 51.7 & 48.3 & 6.9 & 13.8 & 79.3 & 34.5 & 3.4 & 62.1 \\
\hline HH Compliance (\%) & & & & & & \multicolumn{3}{|c|}{20.7} & \multicolumn{3}{|c|}{37.9} \\
\hline \multicolumn{12}{|c|}{ Overall HH Compliance $(\%)=29.3 \%$} \\
\hline
\end{tabular}

Table 2: Hand hygiene practice in A1 Surgical ICU.

\begin{tabular}{|c|c|c|c|c|}
\hline Total Patients & Patients with Infection & Patients colonized & Total Positive Isolates & $\begin{array}{c}\text { Positive Isolate causing } \\
\text { infection }\end{array}$ \\
\hline 29 & 25 & 4 & 76 & 64 \\
\hline$\%$ & 86.2 & 13.8 & 12 & 84.2 \\
\hline
\end{tabular}

Table 3: Classification of positive isolates from A1 Surgical ICU patients.

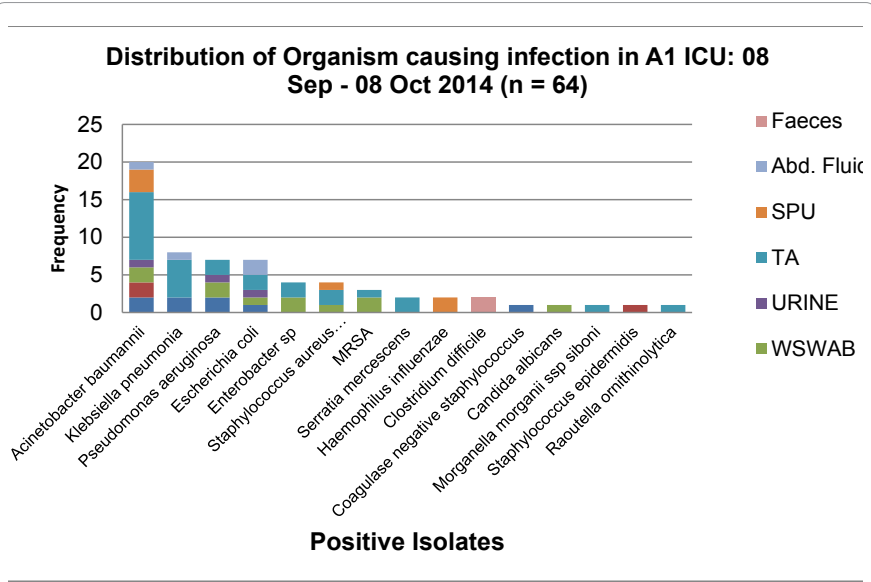

Figure 1: Distribution of organism causing infection.

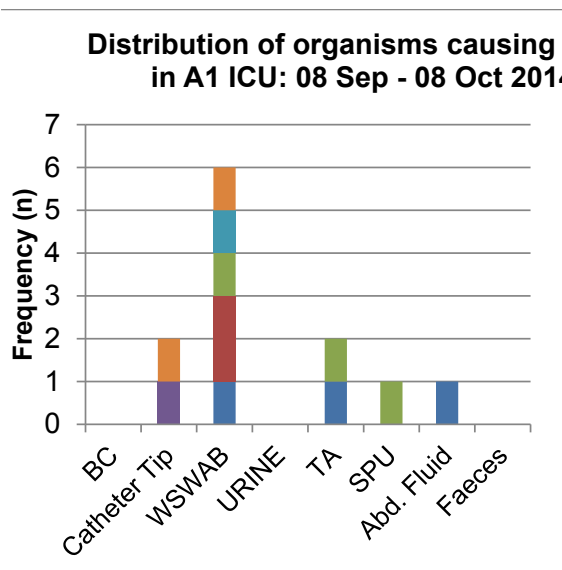

Sample Sites

Figure 2: Distribution of organism causing colonization.

IPC practitioner. $89.7 \%(n=29)$ of patients with HAI infections were isolated in an open ward (Table 5). Infections caused by Acinetobacter baumannii represented $31 \%$ of all infections (Table 6). The crude

\begin{tabular}{|c|c|c|c|c|c|c|}
\hline & BSI & SSI & UTI & LRTI & $\begin{array}{c}\text { C. diff } \\
\text { Infection }\end{array}$ & TOTAL \\
\hline Acinetobacter baumannii & 4 & 2 & 1 & 11 & 0 & 18 \\
\hline Klebsiella pneumoniae & 2 & 0 & 0 & 5 & 0 & 7 \\
\hline MRSA & 1 & 3 & 0 & 4 & 0 & 8 \\
\hline Pseudomonas aeruginosa & 2 & 2 & 1 & 2 & 0 & 7 \\
\hline CNS & 1 & 0 & 0 & 0 & 0 & 1 \\
\hline Escherichia coli & 0 & 2 & 0 & 1 & 0 & 3 \\
\hline Enterobacter $s p$ & 0 & 2 & 0 & 2 & 0 & 4 \\
\hline Candida albicans & 0 & 1 & 0 & 0 & 0 & 1 \\
\hline Haemophilus influenzae & 0 & 0 & 0 & 2 & 0 & 2 \\
\hline $\begin{array}{c}\text { Morganella morganii ssp } \\
\text { siboni }\end{array}$ & 0 & 0 & 0 & 1 & 0 & 1 \\
\hline Raoultella ornithinolytica & 0 & 0 & 0 & 1 & 0 & 1 \\
\hline Serratia mercescens & 0 & 0 & 0 & 2 & 0 & 2 \\
\hline Clostridium difficile & 0 & 0 & 0 & 0 & 3 & 3 \\
\hline TOTAL & 10 & 12 & 2 & 31 & 3 & 58 \\
\hline
\end{tabular}

Table 4: Distribution of organism by type of HAI.

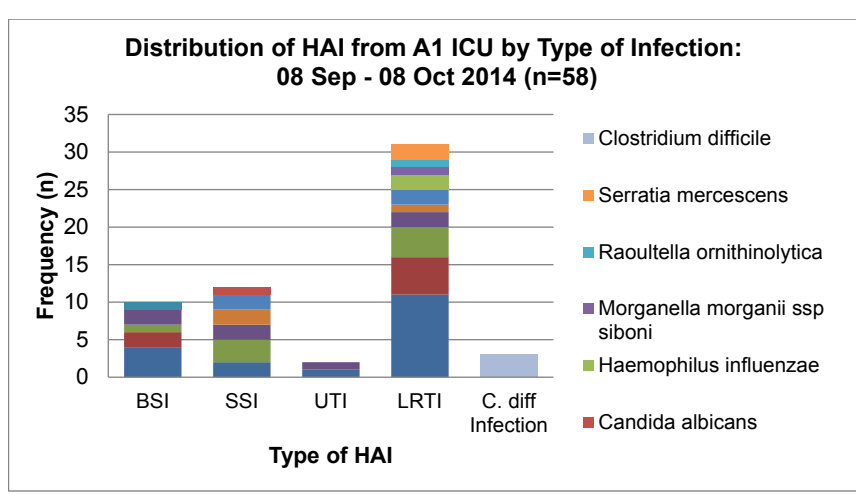

Figure 3: Distribution of HAl by type of infection.

infection was 153.0 infections per 1000 IP-Days per month. LRTI was the highest with 81.8 infections per 1000 IP-Days per month. There were 31.7 infections per 1000 IP-Days per month for SSI. VAP incidence density was 12.3 infections per 1000 ventilator-days per month, while CAUTI incidence density was 7.9 infections per 1000 
Citation: Hakizimana B (2017) Surveillance of Healthcare-Associated infections (HAI) in an Adult Surgical Intensive Care Unit (ICU) in the Republic of South Africa. J Infect Dis Med 2: 115. doi: 10.4172/2576-1420.1000115

Page 4 of 6

\begin{tabular}{|c|c|c|}
\hline IPC Precautions Required & Frequency (n=29) & $\%$ \\
\hline Standard (Only) & 1 & 3.4 \\
\hline Contact & 28 & 96.6 \\
\hline Droplet & 0 & 0 \\
\hline Airborne & 0 & 0 \\
\hline When initiated? & Frequency (n=29) & $\%$ \\
\hline At admission & 1 & 3.4 \\
\hline After getting instructions from IPC Practitioner & 28 & 96.6 \\
\hline Not initiated yet & 0 & 0 \\
\hline Patient Placement & Frequency (n=29) & $\%$ \\
\hline single room & 0 & 0 \\
\hline 2 bedded-room & 3 & 10.3 \\
\hline Cohort & 0 & 0 \\
\hline open ward & 26 & 89.7 \\
\hline
\end{tabular}

Table 5: MDR organism containment practice in A1 Surgical ICU.

\begin{tabular}{|c|c|c|c|c|c|c|}
\hline & BSI & SSI & UTI & LRTI & \begin{tabular}{|c|} 
C. diff \\
Infection
\end{tabular} & TOTAL \\
\hline Acinetobacter baumannii & 4 & 2 & 1 & 11 & 0 & 18 \\
\hline Klebsiella pneumoniae & 2 & 0 & 0 & 5 & 0 & 7 \\
\hline MRSA & 1 & 3 & 0 & 4 & 0 & 8 \\
\hline Pseudomonas aeruginosa & 2 & 2 & 1 & 2 & 0 & 7 \\
\hline CNS & 1 & 0 & 0 & 0 & 0 & 1 \\
\hline Escherichia coli & 0 & 2 & 0 & 1 & 0 & 3 \\
\hline Enterobacter $s p$ & 0 & 2 & 0 & 2 & 0 & 4 \\
\hline Candida albicans & 0 & 1 & 0 & 0 & 0 & 1 \\
\hline Haemophilus influenzae & 0 & 0 & 0 & 2 & 0 & 2 \\
\hline $\begin{array}{c}\text { Morganella morganii ssp } \\
\text { siboni }\end{array}$ & 0 & 0 & 0 & 1 & 0 & 1 \\
\hline Raoultella ornithinolytica & 0 & 0 & 0 & 1 & 0 & 1 \\
\hline Serratia mercescens & 0 & 0 & 0 & 2 & 0 & 2 \\
\hline Clostridium difficile & 0 & 0 & 0 & 0 & 3 & 3 \\
\hline TOTAL & 10 & 12 & 2 & 31 & 3 & 58 \\
\hline IP-Days & 379 & 379 & 379 & 379 & 379 & 379 \\
\hline Incidence density & 26.4 & 31.7 & 5.3 & 81.8 & 7.9 & 153 \\
\hline
\end{tabular}

Table 6: HAl incidence density by type of Infection and by organism.

catheter-days (Table 7). There was no CLABSI case during this period. $65.4 \%(n=78)$ of all isolated organisms causing infections were multidrug-resistant (Table 8). The median age of patients with HAI was 44.5 years and interquartile range $(\mathrm{IQR})=30-59$. The male patients represented $83.3 \%(n=24)$ of HAI cases. $33.3 \%(n=24)$ of HAI cases had hypertension, while HIV was found in $25.0 \%$ of patients with HAI. Among patients with HAI, $91.7 \%$ of them had indwelling urinary catheter in situ, $41.7 \%$ had central line, $95.8 \%$ had peripheral line and 91.7\% had endotracheal tube in situ (Table 9). 50\% ( $n=24)$ of patients with HAI were admitted for clean-contaminated wounds while $37.5 \%$ were admitted for contaminated wounds. No patient with clean wound found with infection. Gunshot wounds represented 25\% $(n=24)$ of the admission reasons (Figures 4-6).

Looking at all the patients recruited in the study ( $n=29)$ : $55 \%$ (16) of patients were discharged as cured, $28 \%$ (8) were improved and moved to other wards in the hospital. 10\% (3) were deceased, while $7 \%$ (2) were still in the same ward on the $15^{\text {th }}$ October 2014, which was the last day of patient follow up in this project (Figure 7).

\begin{tabular}{|c|c|c|c|}
\hline & CLABSI & CAUTI & VAP \\
\hline Acinetobacter baumannii & 0 & 1 & 2 \\
\hline Klebsiella pneumoniae & 0 & 0 & 1 \\
\hline Pseudomonas aeruginosa & 0 & 1 & 0 \\
\hline Escherichia coli & 0 & 1 & 0 \\
\hline Morganella morganii ssp siboni & 0 & 0 & 1 \\
\hline TOTAL CASES & 0 & 3 & 4 \\
\hline Device-Days & 359 & 378 & 324 \\
\hline Incidence density & 0 & 7.9 & 12.3 \\
\hline
\end{tabular}

Table 7: Device-associated infection incidence density.

\begin{tabular}{|c|c|c|c|c|c|c|}
\hline \multirow{2}{*}{ Organism $(n=78)$} & \multicolumn{5}{|c|}{ Susceptibility } & \multirow{2}{*}{$\begin{array}{c}\text { MDR } \\
(\%)\end{array}$} \\
\hline & S & ESBL & CRO & MRSA & NCMDRO & \\
\hline Acinetobacter baumannii & 0 & 0 & 23 & 0 & 0 & 100 \\
\hline Klebsiella pneumonia & 1 & 5 & 2 & 0 & 0 & 87.5 \\
\hline Pseudomonas aeruginosa & 5 & 2 & 2 & 0 & 0 & 44.4 \\
\hline Escherichia coli & 11 & 0 & 0 & 0 & 0 & 0 \\
\hline Enterobacter sp & 2 & 2 & 0 & 0 & 0 & 50 \\
\hline Staphylococcus aureus & 1 & 0 & 0 & 9 & 0 & 90 \\
\hline Serratia mercescens & 2 & 0 & 0 & 0 & 0 & 0 \\
\hline Haemophilus influenzae & 2 & 0 & 0 & 0 & 0 & 0 \\
\hline Clostridium difficile & 0 & 0 & 0 & 0 & 3 & 100 \\
\hline $\begin{array}{l}\text { Coagulase negative } \\
\text { staphylococcus }\end{array}$ & 1 & 0 & 0 & 0 & 0 & 0 \\
\hline Candida albicans & 1 & 0 & 0 & 0 & 0 & 0 \\
\hline Morganella morganii ssp siboni & 0 & 1 & 0 & 0 & 0 & 100 \\
\hline Staphylococcus epidermidis & 0 & 0 & 0 & 0 & 1 & 100 \\
\hline Raoultella ornithinolytica & 1 & 0 & 0 & 0 & 0 & 0 \\
\hline Providencia stuartii & 0 & 0 & 1 & 0 & 0 & 100 \\
\hline TOTAL & 27 & 10 & 28 & 9 & 4 & 65.4 \\
\hline
\end{tabular}

Table 8: Resistance patterns among HAI patients in A1 Surgical ICU.

Looking at the patients with HAI ( $n=24): 54 \%$ (13) of patients were discharged as cured, $29 \%$ (7) were improved and moved to other wards in the hospital. $8 \%$ (2) were deceased, and 9\% (2) were still in the same ward on the $15^{\text {th }}$ October 2014, which was the last day of patient follow up in this project (Figure 8).

\section{Discussion}

HAI rates in the present project were compared to the rates in the NHSN data [11]. For LRTI and SSI; the rates in the A1 Surgical ICU were higher than the $50^{\text {th }}$ percentile of the NHSN data. There was no case of CLABSI found in the unit during the project period. This was much better compared to what reported by International Nosocomial Infection Control Consortium (INICC) report and the NHSN study which is $6.8 / 1000$ device-days in ICUs $[11,12]$. The overall VAP rate in the present project was higher than of the NHSN report (12.3 vs. $3.3 / 1000$ device-days), and lower than the INICC rate of $15.8 / 1000$ device-days [13]. In addition, CAUTI rate (7.9/1000 device-days) is closer to the INICC rate (6.3/1000 device-days) and higher than the NSHN data $[12,13]$. In the surveillance program of nosocomial infections in Catalonia (VINCat Program), the incidence rates of VAP ranged from 7.2 to 10.7 episodes/1000 ventilator-days, and the rate of 
Citation: Hakizimana B (2017) Surveillance of Healthcare-Associated infections (HAI) in an Adult Surgical Intensive Care Unit (ICU) in the Republic of South Africa. J Infect Dis Med 2: 115. doi: 10.4172/2576-1420.1000115

\begin{tabular}{|c|c|c|c|}
\hline Risk Factors & & $\begin{array}{l}\text { Frequency } \\
(n=24)\end{array}$ & $\%$ \\
\hline Median age of patients (years) & & \multicolumn{2}{|c|}{$44.5(I Q R=30-59)$} \\
\hline \multirow{2}{*}{ Gender } & Male & 20 & 83.3 \\
\hline & Female & 4 & 16.7 \\
\hline Diabetes & & 3 & 12.5 \\
\hline Hypertension & & 8 & 33.3 \\
\hline Obesity & & 2 & 8.3 \\
\hline Malnutrition & & 0 & 0 \\
\hline HIV & & 6 & 25 \\
\hline Indwelling Urinary Catheter in situ & & 22 & 91.7 \\
\hline Central line(s) in situ & & 10 & 41.7 \\
\hline Peripheral line(s) in situ & & 23 & 95.8 \\
\hline ET tube in situ & & 22 & 91.7 \\
\hline \multirow{4}{*}{ Wound Contamination } & W1 & 0 & 0 \\
\hline & W2 & 12 & 50 \\
\hline & W3 & 9 & 37.5 \\
\hline & W4 & 3 & 12.5 \\
\hline
\end{tabular}

Table 9: Risk factors among patients with $\mathrm{HAl}$ in A1 surgical ICU.

\section{HAl rate in A1 ICU: TBH, 08 Sep - 08 Oct 2014}

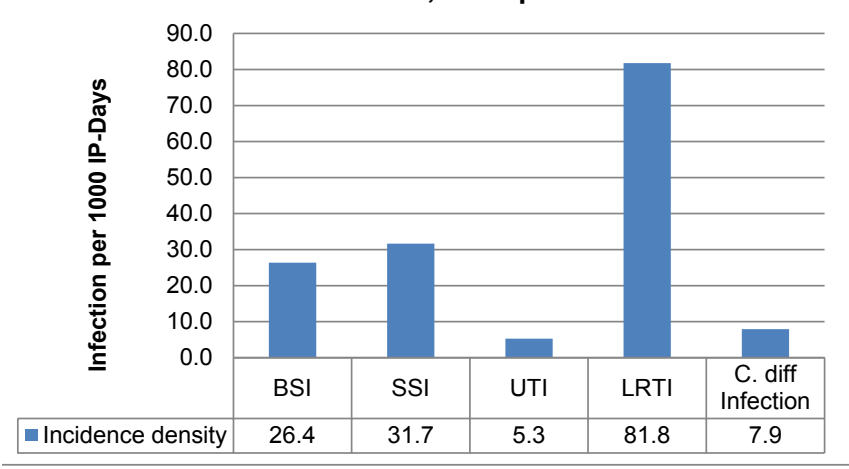

Figure 4: HAl incidence density in A1 surgical ICU by type of infection.

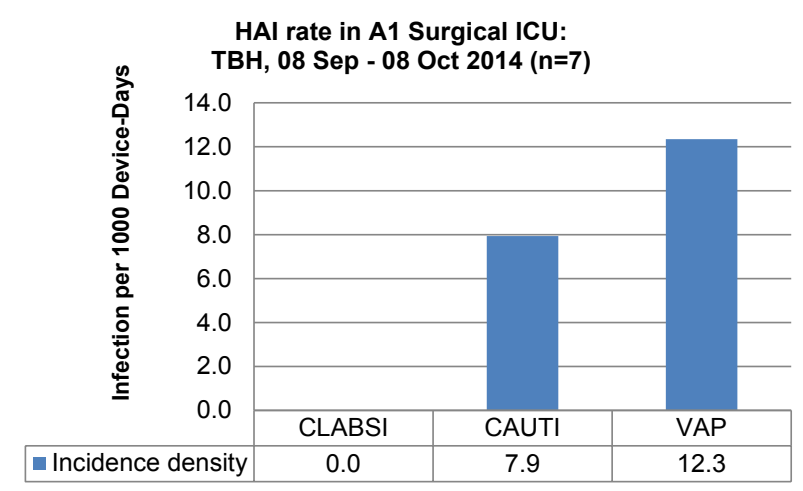

Figure 5: Device-associated infection incidence density.

CLABSI ranged from 1.9 to 2.7 episodes/1000 central venous catheterdays [14]. The variation in the HAI rates between the different studies cited could be related to the difference in the setting of the involved hospitals and the different application of preventive measures, e.g., bundles of care. It was estimated that HAI can be reduced by $30 \%$ [13]. The institution of HAI surveillance is a recognized measure to reduce these infections [16]. The emergence of the bundle of care (sets of

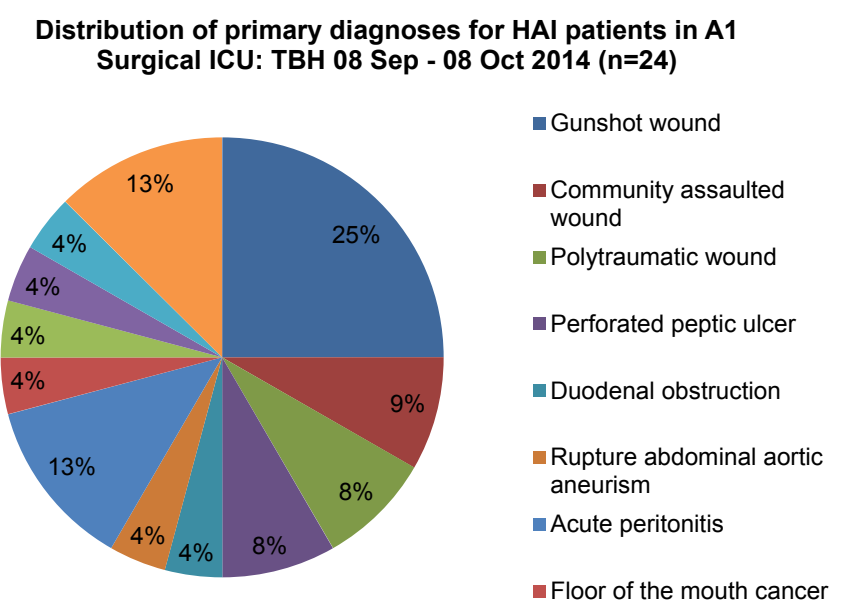

Figure 6: Distribution of primary diagnoses among patients with HAI.

\section{Outcome of patients followed in A1} Surgical ICU: 08 Sep - 08 Oct $2014(n=29)$

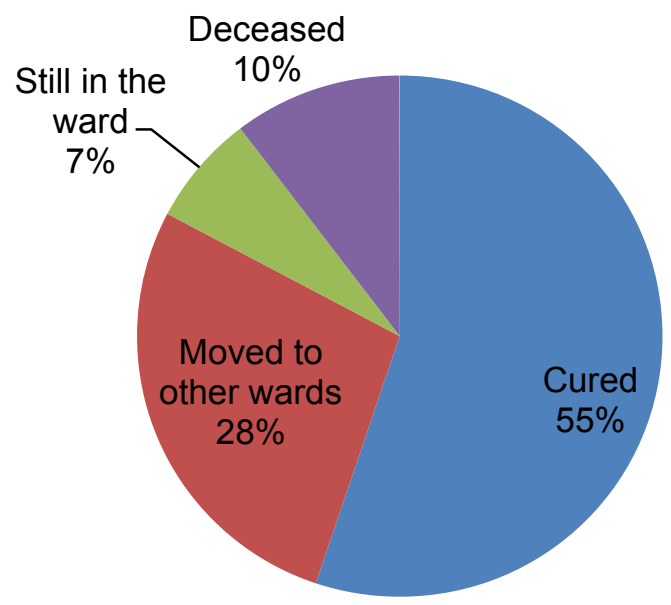

Figure 7: Distribution of outcome among all patients of the study.

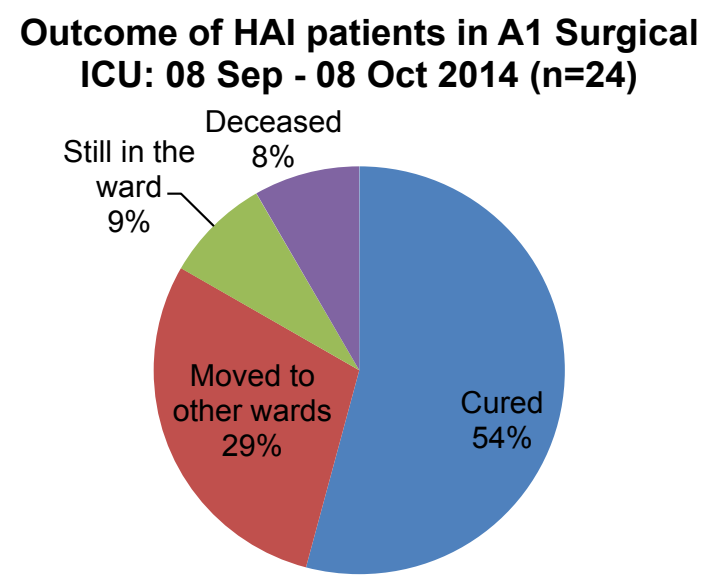

Figure 8: Distribution of outcome among patients with HAl. 
Citation: Hakizimana B (2017) Surveillance of Healthcare-Associated infections (HAI) in an Adult Surgical Intensive Care Unit (ICU) in the Republic of South Africa. J Infect Dis Med 2: 115. doi: 10.4172/2576-1420.1000115

evidence-based, high-impact interventions) concepts has added value to the scope of improvement and reduction in the rates of HAIs. In a study from Saudi Arabia, the VAP rate was 19.1 per 1000 ventilatordays in 2003 and decreased to 6.3 per 1000 ventilator-days in 2009 [17]. It was previously demonstrated that the application of the VAP bundle resulted in a significant reduction in the rates of VAP over time [18]. That study was conducted in 2006 to 2008 and since then the rate of VAP has remained low at 1.3 per 1000 device-days compared to 2.2 per 1000 device-days in 2008 [18]. Thus, it is possible to maintain a low rate of VAP over time with diligent application and incorporation of the bundle in the daily routine, as well as an increase in the rate of compliance with hand hygiene [19].

\section{Conclusion}

The findings from the study showed the high rates of HAI rates, especially for LRTI (81.8/1000 IP-Days), SSI (31.7/1000 IP-Days) and BSI (26.4/1000 IP-Days). Looking at the organism resistance pattern, we found that $65.4 \%$ were MDR organisms. Hand hygiene compliance was very scared (29.3\%). CLABSI care bundle was the only single bundle of care implemented in A1 Surgical ICU, and was effective. Generally, IPC isolation precautions were put in place late, just after being instructed by IPC practitioners from the Unit for Infection Prevention and Control (UIPC). This means that the patients with infections were stayed with other patients in an open ward because either there was no single room available or still waiting instructions from IPC practitioners. Admitting together patients with HAI and those without infections in the same ward, increases the risk of cross-infection between patients. Lack of adherence to IPC precautions put patients at high risk of HAIs. Bundles of care other than CLABSI such as VAP, CAUTI should be implemented to reduce HAIs. Most importantly, standard precautions should be adhered to. Healthcare providers (doctors and nurses) should be equipped with the required knowledge and skills in IPC and be encouraged to adhere always to standard precautions and to start transmission-based precautions as soon as possible.

\section{Acknowledgements}

The authors are grateful for the support from the manager, medical doctors and nurses of A1 Surgical ICU at Tygerberg Hospital.

I would also like to convey my special gratitude to Mrs Magda Maureen Mocke for the supervision and guidance during this project.

My acknowledgement also goes to Prof. Shaheen Mehtar for encouragement and academic support during this project.

\section{References}

1. Centers for Disease Control (1989) CDC definitions for nosocomial infections, 1988. Am Rev Respir Dis 139: 1058-1059.

2. Horan TC, Gaynes RP (2004) Surveillance of nosocomial infections. In: Mayhall CG (ed.). Hospital epidemiology and infection control (3rd edn). Lippincott Williams \& Wilkins, Philadelphia. pp: 1659-1702.
3. Vincent $\mathrm{JL}$ (2003) Nosocomial infections in adult intensive-care units. Lancet 361: 2068-2077.

4. Chaberny IF, Sohr D, Rüden H, Gastmeier P (2007) Development of a Surveillance system for methicillin-resistant staphylococcus aureus in german hospitals. Infection Control and Hospital Epidemiology 28: 446-452.

5. World Health Organisation (2011) Report on the Burden of endemic health care-associated infection worldwide. A systematic review of the literature.

6. Pittet, D (2001) Compliance with hand disinfection and its impact on hospitalacquired infections. J Hosp Infect 48: S40-S46.

7. Pittet D (2000) Improving compliance with hand hygiene in hospitals. Infect Control Hosp Epidemiol 21: 381-386.

8. Pittet, D, Allegranzi B, Sax H, Dharan S, Pessoa-Silva CL, et al. (2006) Evidence-based model or hand transmission during patient care and the role of improved practices. Lancet Infect Dis 6: 641-652.

9. Sax H, Allegranzi B, Uçkay I, Larson E, Boyce J, et al. (2007) My five moments for hand hygiene: A user-centred design approach to understand, train, monitor and report hand hygiene. J Hosp Infect 67: 9-21.

10. http://www.who.int/gpsc/5may/registration_update/en/

11. Horan TC, Andrus M, Dudeck MA (2008) CDC/NHSN surveillance definition of health care-associated infection and criteria for specific types of infections in the acute care setting. Am J Infect Control 36: 309-332.

12. Dudeck MA, Horan TC, Peterson KD, Allen-Bridson K, Morrell G, et al. (2011) National Healthcare Safety Network (NHSN) Report, data summary for 2010, device-associated module. Am J Infect Control 39: 798-816.

13. Navoa-Ng JA, Berba R, Galapia YA, Rosenthal VD, Villanueva VD, et al. (2011) Device-associated infection rates in adult, pediatric, and neonatal intensive care units of hospitals in the Philippines: International Nosocomial Infection Control Consortium (INICC) findings. Am J Infect Control 39: 548-554.

14. Valle`s J, Limo'n E, Dı'az E, Palomar M, Barcenilla F, et al. (2012) Deviceassociated infection rates in adult intensive care units in Catalonia: VINCat Program findings. Enferm Infecc Microbiol Clin 30:33-38.

15. Haley RW, Quade D, Freeman HE, Bennett JV (1980) The SENIC project study on the efficacy of nosocomial infection control (SENIC Project) summary of study design. Am J Epidemiol 111: 472-485.

16. Gastmeier P, Schwab F, Sohr D, Behnke M, Geffers C (2009) Reproducibility of the surveillance effect to decrease nosocomial infection rates. Infect Control Hosp Epidemiol 30: 993-999.

17. Al-Dorzi HM, El-Saed A, Rishu AH, Balkhy HH, Memish ZA, et al. (2012) The results of a 6-year epidemiologic surveillance for ventilator-associated pneumonia at a tertiary care intensive care unit in Saudi Arabia. Am J Infect Control 40: 794-799.

18. Al-Tawfiq JA, Abed MS (2010) Decreasing ventilator-associated pneumonia in adult intensive care units using the Institute for Healthcare Improvement bundle. Am J Infect Control 38: 552-556.

19. Al-Tawfiq JA, Abed MS, Al-Yami N, Birrer RB (2013) Promoting and sustaining a hospital-wide, multifaceted hand hygiene program resulted in significant reduction in health care-associated infections. Am J Infect Control 41: 482-486.

20. Altemeier WA, Burke JF, Pruitt BA, Sandusky WR (1984) Manual on control of infection in surgical patients (2nd edn.). JB Lippincott, Philadelphia.

21. Strengthening Pharmaceutical Systems (2009) Infection control assessment tool (2nd edn.). 